\title{
AVALIAÇÃo DA EFICÁCIA DE MÉtOdOS PREVENTIVOS ADOTADOS PELOS ALUNOS DA UFPR
}

Etieny de Fátima Marques MEDUNA, Renata TASSI, Camille Chaiana FACCIN, Maria da Graça Kfouri LOPES

A deficiência na higiene bucal dos pacientes faz com que se manifestem doenças bucais como a cárie dental e a doença periodontal. Por este motivo devem ser tomadas medidas preventivas na abordagem dos pacientes. Em muitos casos ainda são usados apenas os métodos curativos de saúde bucal, e há deficiência quanto aos métodos preventivos; visto que na revisão de literatura realizada, há relatos da ineficácia do método preventivo utilizado pelo cirurgião-dentista, pela falta de educação em saúde bucal e maneira incorreta e pouco enfatizada na informação sobre a higiene bucal. Nesta pesquisa realizada por meio de questionários respondidos por 26 alunos da Clínica Integrada do ano de 2007/1 da UFPR, foi confirmada a deficiência da prática educativa, muitos alunos relataram que apesar de orientarem seus pacientes quanto à higiene bucal, através de comunicação, explicação em macro-modelos, evidenciação de placa, não obtiveram resultados positivos em todos os pacientes atendidos neste período. Devem-se analisar os métodos utilizados para que o método curativo não supere o preventivo, o qual é o objetivo a ser alcançado pelos profissionais da saúde, principalmente da saúde bucal, onde esta situação é mais evidente. 